\title{
SURVEI PERILAKU MASYARAKAT TERHADAP POPULASI TUNGAU DEBU RUMAH DI KELURAHAN PERKAMIL KECAMATAN PAAL 2 KOTA MANADO
}

\author{
${ }^{1}$ Monalisa Rambing \\ ${ }^{2}$ J.Runtuwene \\ ${ }^{2}$ J.S.B.Tuda
}

\author{
${ }^{1}$ Kandidat Skripsi Fakultas Kedokteran Universitas Sam Ratulangi Manado \\ ${ }^{2}$ Bagian Parasitologi Fakultas Kedokteran Universitas Sam Ratulangi Manado \\ Email:monanda15@gmail.com
}

\begin{abstract}
House dust mite are insects that can cause allergies in susceptible people. Population of dust mites in the home depends on factors such as the level of the sea, an area with a longer summer than rainy season, a variety of animals in the house, the house is dirty and a lot of dust, as well as the temperature and humidity of the area. Manado city has several of the factors. Purpose of the study is to investigate the people's behavior of the population of house dust mites in Perkamil village sub-district of Paal 2 Manado city. Result obtained was 34,86\% which shows that people's knowledge about house dust mites are still lacking. The result of attitude is $97,09 \%$ indicated public attitudes towards the prevention and eradication of house dust mite is good. And result of the public action showed $75,96 \%$ of the community action efforts to prevent and eradicate house dust mites is enough. Necessary education from health care workers about house dust mites and allergic diseases, prevention and eradication, so that the knowledge that still low will be better and the action that will be good enough.
\end{abstract}

Keywords : Behavior, Peoples, House Dust Mites

\begin{abstract}
Abstrak: Tungau debu rumah (TDR) adalah serangga yang dapat menyebabkan alergi pada orang yang rentan. Populasi tungau debu di dalam rumah bergantung pada faktor - faktor, seperti tinggi rendahnya rumah dari permukaan laut, daerah dengan musim panas yang lebih panjang dari musim hujan, adanya berbagai macam binatang di dalam rumah, rumah yang kotor dan banyak debu, serta suhu dan kelembaban daerah tersebut. Kota Manado memiliki beberapa faktor tersebut. Tujuan penelitian adalah untuk mengetahui perilaku masyarakat terhadap populasi tungau debu rumah di Kelurahan Perkamil Kecamatan Paal 2 Kota Manado. Hasil yang didapatkan adalah 34,86\% menunjukkan pengetahuan masyarakat Kelurahan Perkamil mengenai Tungau Debu Rumah masih kurang. Untuk sikap didapatkan hasil 97,09\% menunjukkan sikap masyarakat terhadap upaya pencegahan dan pemberantasan Tungau Debu Rumah sudah baik. Dan untuk tindakan masyarakat didapatkan hasil 75,96\% menunjukkan tindakan masyarakat terhadap upaya pencegahan dan pemberantasan Tungau Debu Rumah sudah cukup. Perlu dilakukan penyuluhan dari petugas kesehatan tentang Tungau Debu Rumah dan penyakit Alergi, cara pencegahan dan pemberantasan, agar pengetahuan masih rendah akan menjadi lebih baik lagi dan tindakan masyarakat yang sudah cukup akan menjadi baik.
\end{abstract}

Kata Kunci : Perilaku, Masyarakat, Tungau Debu Rumah

Tungau debu rumah (TDR) adalah serangga yang dapat menyebabkan alergi pada orang yang rentan. Dermatophagoides pteronyssinus adalah tungau debu rumah yang merupakan alergen hirup dan dapat menyebabkan asma bronchial. ${ }^{1}$

Tungau spesies $D$. pteronyssinus paling banyak terdapat di daerah tropis dan subtropis di dunia selain tungau spesies Blomia 
tropicalis. Di Taiwan, D. pteronyssinus merupakan spesies tungau terbanyak di banding $B$. tropicalis. Pada musim panas (Juli-Agustus) populasi tungau meningkat, sedangkan pada musim hujan populasi menurun secara signifikan. Selain di Taiwan, dilaporkan bahwa TDR spesies $D$. pteronyssinus banyak terdapat di beberapa negara seperti, Singapura, Colombia, dan India. $^{2}$

Hasil penelitian TDR di Semarang membuktikan bahwa populasi TDR pada kasur kapuk lebih banyak dari pada populasi TDR pada kasur non kapuk. Di Indonesia, sebagian besar masyarakatnya masih menggunakan kasur berbahan kapuk sebagai alas tidurnya. ${ }^{3}$ Selain kasur, TDR banyak terdapat di sprei, bantal, karpet, dan lantai. ${ }^{1,3,4,5}$

Kota Manado memiliki beberapa faktor yang dapat mempengaruhi populasi tungau debu rumah, yaitu keadaan iklim Kota Manado, tahun 2006 suhu udara pada siang hari rata-rata $29,40^{\circ}-32,20^{\circ} \mathrm{C}$ dan rata-rata kelembaban udara relatif tinggi antara $75 \%$ pada bulan Juni sampai $92 \%$ pada bulan Desember. ${ }^{6}$ Sedangkan tahun 2010 suhu udara rata-rata pada siang hari berkisar antara $31,40^{\circ}$ sampai $33,70^{\circ} \mathrm{C}$ dan kelembaban udara relatif tinggi dengan rata-

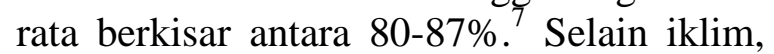
topografi Kota Manado secara keseluruhan $94,53 \%{ }^{6}$ terletak pada ketinggian $0-240 \mathrm{~m}$ dari permukaan laut, ${ }^{5,6}$ yang berarti Kota Manado termasuk dalam karakter dataran rendah. ${ }^{7}$ Dengan adanya faktor-faktor tersebut menunjukkan bahwa dapat terjadi peningkatan kepadatan populasi TDR di Kota Manado.

Adanya masalah di atas, membuat penulis tertarik untuk melakukan penelitian bagaimana perilaku masyarakat terhadap populasi tungau debu rumah di sekitar rumah penduduk di Kelurahan Perkamil Kecamatan Paal 2 Kota Manado.

\section{METODE PENELITIAN}

Penelitian ini merupakan jenis penelitian deskriptif dengan metode survey. Populasi dalam penelitian ini adalah seluruh kepala keluarga yaitu 1875 KK yang tinggal di Kelurahan Perkamil. Besar sampel yang diambil $95 \mathrm{KK}$ dan menggunakan teknik Simple Random Sampling. Instrumen penelitian adalah kuesioner atau daftar pertanyaan mengenai pengetahuan, sikap dan tindakan masya-rakat terhadap tungau debu rumah. Data yang diperoleh dianalisis dengan cara Analisis Univariat. Analisis Univariat ber-tujuan untuk memperoleh gambaran setiap karakteristik masingmasing variabel yang diteliti.

\section{HASIL DAN PEMBAHASAN}

\section{Karakteristik Responden}

Untuk mengetahui distribusi pendu-duk berdasarkan kelompok umur, jenis kelamin, tingkat pendidikan dan jenis pekerjaan dapat dilihat dalam tabel berikut ini.

Tabel 1. Distribusi responden menurut umur

\begin{tabular}{lll}
\hline Keterangan & Jumlah & \% \\
\hline$<20$ & 2 & 2.1 \\
$20-39$ & 28 & 29.5 \\
$40-59$ & 52 & 54.7 \\
$\geq 60$ & 13 & 13.7 \\
\hline Jumlah & 95 & 100 \\
\hline
\end{tabular}

Dari Tabel 1, terlihat umur responden yang terbanyak adalah yang berumur 40 59 tahun dengan jumlah 52 responden (54,7\%).

Tabel 2. Distribusi responden berdasarkan jenis kelamin

\begin{tabular}{lll}
\hline Keterangan & Jumlah & \% \\
\hline Pria & 35 & 36.8 \\
Wanita & 60 & 63.2 \\
\hline Jumlah & 95 & 100 \\
\hline
\end{tabular}

Dari Tabel 2, terlihat jenis kelamin responden yang terbanyak adalah wanita dengan jumlah 60 responden $(63,2 \%)$. 
Tabel 3. Distribusi Responden berdasarkan pekerjaan

\begin{tabular}{lll}
\hline Keterangan & Jumlah & $\mathbf{\%}$ \\
\hline IRT & 26 & 27.4 \\
PNS & 19 & 20 \\
Swasta & 15 & 15.8 \\
Pensiunan & 13 & 13.7 \\
Wiraswasta & 7 & 7.4 \\
Mahasiswa & 6 & 6.3 \\
Guru & 5 & 5.3 \\
Pendeta & 2 & 2.1 \\
TNI & 1 & 1.1 \\
Buruh & 1 & 1.1 \\
\hline Jumlah & 95 & 100 \\
\hline
\end{tabular}

Dari Tabel 3, terlihat pekerjaan responden yang terbanyak adalah Ibu Rumah Tangga dengan jumlah 26 orang $(27,4 \%)$.

Tabel 4. Distribusi responden berdasarkan pendidikan terakhir

\begin{tabular}{lll}
\hline Keterangan & Jumlah & \% \\
\hline tamat SMP & 4 & 4.2 \\
tamat SMA & 56 & 58.9 \\
$\begin{array}{l}\text { tamat Akademi/Perguruan } \\
\text { tinggi }\end{array}$ & 35 & 36.8 \\
\hline Jumlah & 95 & 100 \\
\hline
\end{tabular}

Dari Tabel 4, terlihat pendidikan terakhir responden yang terbanyak adalah tamatan SMA dengan jumlah 56 orang $(58,9 \%)$.

Tabel 5. Distribusi responden berdasarkan status kependudukan

\begin{tabular}{lll}
\hline Keterangan & Jumlah & \% \\
\hline Asli & 84 & 88.4 \\
Pendatang & 11 & 11.6 \\
\hline Jumlah & 95 & 100 \\
\hline
\end{tabular}

Dari Tabel 5, terlihat status kependudukan responden yang terbanyak adalah penduduk asli dengan jumlah 84 orang $(88,4 \%)$.

\section{Pengetahuan}

Paling banyak responden tidak pernah mendengar informasi mengenai Tungau Debu Rumah. Hal ini menunjukkan bahwa peran petugas kesehatan masih belum efisien dalam upaya penyebarluasan informasi tentang Tungau Debu Rumah. Karena banyak responden tidak pernah mendengar informasi mengenai Tungau Debu Rumah, maka banyak responden yang juga tidak tahu mengenai penyakit yang disebabkan oleh Tungau Debu Rumah. Banyak responden juga tidak tahu mengenai ukuran, makanan dan tempat yang banyak ditemukan Tungau Debu Rumah.

Hasil penelitian juga didapatkan bahwa sebanyak 55 responden (57,9\%) tidak tahu mengenai penyakit apa yang dapat disebabkan oleh Tungau Debu Rumah. Dan sebanyak 40 responden (42,1\%) menjawab Alergi sebagai akibat dari Tungau Debu Rumah. Tungau debu merupakan alergen hirup sebagai faktor pencetus timbulnya penyakit alergi. ${ }^{1}$ Hal ini menunjukkan bahwa pengetahuan responden mengenai penyakit yang disebabkan oleh Tungau Debu Rumah masih kurang.

Berbahaya atau tidaknya penyakit akibat Tungau Debu Rumah, 63 responden (66,3\%) menjawab tidak tahu. Sebanyak 25 responden (26,3\%) memilih dapat menyebabkan penyakit pada orang yang rentan atau sensitif saja. Sedangkan yang menjawab sangat berbahaya dan mematikan sebanyak 6 responden (6,3\%) dan 1 responden $(1,1 \%)$ yang menjawab tidak berbahaya. Pengetahuan responden tentang Tungau Debu Rumah dapat menyebabkan penyakit pada orang yang rentan terlihat masih kurang.

Pengetahuan responden mengenai tempat yang banyak ditemukan Tungau Debu Rumah, sebanyak 55 responden (57,9\%) tidak tahu, sebanyak 36 responden $(37,9 \%)$ menjawab kasur, seprei, dan sofa. 
Untuk yang menjawab lemari pakaian, meja makan dan hiasan rumah ada 4 responden(4,2\%). Didalam rumah Tungau Debu Rumah paling banyak dijumpai pada perabot kamar tidur dan paling sedikit pada hiasan rumah. ${ }^{4}$ Hal ini menunjukkan sebagian responden belum mengetahui tempat yang banyak ditemukan Tungau Debu Rumah.

Dari hasil penelitian mengenai pengetahuan responden tentang ukuran dari Tungau Debu Rumah, sebanyak 57 responden (60\%) menjawab tidak tahu, sebanyak 34 responden (35,8\%) menjawab sangat kecil atau tidak dapat dilihat mata secara langsung, dan 4 responden (4,2\%) menjawab kecil,seukuran nyamuk atau semut kecil. Terlihat sebagian besar responden belum mengetahui ukuran dari Tungau Debu Rumah.

Pengetahuan responden tentang makanan Tungau Debu Rumah, sebanyak 66 responden $(69,5 \%)$ menjawab tidak tahu, sebanyak 14 responden (14,7\%) menjawab daki dan serpihan kulit manusia, 11 responden $(11,6 \%)$ menjawab debu rumah, dan 4 responden $(4,2 \%)$ menjawab seratserat kain. Makanan Tungau Debu Rumah adalah skuama, daki, dan sisa makanan. ${ }^{4}$ Terlihat masih banyak responden yang tidak mengetahui makanan dari Tungau Debu Rumah.

Hasil penelitian mengenai pengetahuan responden tentang cara pemberantasan Tungau Debu Rumah, ada 53 responden (55,8\%) menjawab tidak tahu, ada 39 responden $(41,1 \%)$ menjawab ya, dengan menjaga kebersihan, dan 3 responden $(3,2 \%)$ menjawab ya, dengan melakukan penyemprotan insektisida. Terlihat masih banyak responden yang belum mengetahui cara pemberantasan Tungau Debu Rumah.

Hasil pengetahuan mengenai siapa yang berperan dalam pemberantasan Tungau Debu Rumah, ada 56 responden (58,9\%) menjawab seluruh anggota keluarga, 32 responden $(33,7 \%)$ menjawab tidak tahu, 4 responden $(4,2 \%)$ menjawab pemerintah dan 3 responden (3,2\%) menjawab petugas kesehatan. Hal ini menunjukkan sebagian besar responden tahu bahwa yang berperan dalam pemberantasan Tungau Debu Rumah adalah seluruh anggota keluarga.

Dari hasil perhitungan berdasarkan kriteria penilaian untuk pengetahuan didapatkan hasil 34,86\%. Hal ini menunjukkan bahwa pengetahuan responden mengenai Tungau Debu Rumah masih kurang. Karena itu diperlukan peran petugas kesehatan untuk dapat mengadakan penyuluhan mengenai Tungau Debu Rumah dan Penyakit Alergi.

\section{Sikap}

Dari hasil penelitian, semua responden (100\%) menyatakan setuju bila diadakan penyuluhan tentang Tungau Debu Rumah dan penyakit Alergi oleh petugas kesehatan di lingkungan tempat tinggalnya.

Sebanyak 86 responden (90,5\%) setuju bila penderita Alergi harus segera dibawa ke rumah sakit atau puskesmas terdekat. Sebanyak 5 responden (5,3\%) tidak setuju, 2 responden $(2,1 \%)$ menjawab ragu-ragu, dan 2 responden (2,1\%) menjawab tidak tahu.

Dari hasil penelitian menunjukkan bahwa sebanyak 84 responden $(88,4 \%)$ bersikap setuju untuk membersihkan perabot dengan lap basah. Sedangkan yang menjawab ragu-ragu sebanyak 8 responden $(8,4 \%), 2$ responden (2,1\%) menjawab tidak setuju dan 1 responden (1,1\%) menjawab tidak tahu.

Sebagian besar responden (97,9\%) setuju untuk meletakkan pakaian, buku dan mainan anak dalam lemari tertutup, sedangkan lainnya (2,1\%) menjawab ragu-ragu.

Untuk mengganti seprei seminggu sekali, sebanyak 92 responden (96,8\%) bersikap setuju dan 2 responden (2,1\%) bersikap tidak setuju. Sedangkan yang bersikap ragu-ragu hanya 1 responden $(1,1 \%)$.

Hasil penelitian untuk sikap responden menjemur kasur, bantal dan guling seminggu sekali, 88 responden (92,6\%) menjawab setuju. Sedangkan yang bersikap ragu-ragu ada 7 responden $(7,4 \%)$.

Seluruh responden (100\%) bersikap setuju untuk membuka jendela rumah setiap hari agar sinar matahari dapat masuk ke dalam rumah. 
Dari hasil perhitungan berdasarkan kriteria penilaian didapatkan hasil 97,09\%. Hal ini menunjukkan bahwa sikap responden sudah baik, dimana responden menunjukkan sikap yang positif dalam memberantas Tungau Debu Rumah.

\section{Tindakan}

Tindakan responden untuk menyapu lantai rumah, sebanyak 91 reponden (95,8\%) melakukannya setiap hari, sedangkan 4 responden $(4,2 \%)$ melakukannya kadang-kadang atau secara tidak teratur.

Tindakan responden untuk mengepel lantai rumah, sebanyak 20 responden (21,1\%) melakukannya setiap hari. Sebanyak 44 responden (46,3\%) melakukannya dua kali seminggu, sebanyak 27 responden (28,4\%) melakukannya kadang-kadang atau secara tidak teratur dan sebanyak 4 responden (4,2\%) melakukannya dua kali sebulan.

Tindakan responden untuk membersihkan perabot rumah, sebanyak 42 responden $(44,2 \%)$ melakukannya kadang-kadang atau tidak teratur. Sebanyak 37 responden (38,9\%) melakukannya dua kali dalam seminggu. Sebanyak 13 responden (13,7\%) melakukannya setiap hari dan 3 responden (3,2\%) melakukannya dua bulan sekali.

Tindakan responden berdasarkan cara membersihkan perabot rumah, sebanyak 49 responden $(51,6 \%)$ membersihkan dengan lap basah, sebanyak 42 responden (44,2\%) membersihkan dengan kemoceng, dan 3 responden (3,2\%) membersihkan dengan cara lain seperti sikat atau vacuum cleaner. Sedangkan yang menjawab tidak tahu atau tidak pernah, ada 1 responden $(1,1 \%)$.

Dari hasil penelitian, seluruh responden (100\%) meletakkan pakaian dalam lemari tertutup. Untuk menghindari debu maka pakaian harus diletakkan dalam lemari tertutup.

Tindakan responden berdasarkan tempat meletakkan buku-buku, sebanyak 49 responden $(51,6 \%)$ meletakkannya di lemari terbuka. Sebanyak 26 responden $(27,4 \%)$ meletakkannya di lemari tertutup, sebanyak 18 responden (18,9\%) meletakkannya di meja dan 2 responden (2,1\%) meletakkannya di sembarang tempat.
Tindakan responden mengganti seprei dan sarung bantal, sebanyak 60 responden $(63,2 \%)$ melakukannya sekali seminggu. Sebanyak 20 responden (21,1\%) melakukannya sekali sebulan. Sebanyak 8 responden $(8,4 \%)$ jarang melakukannya dan 7 responden $(7,4 \%)$ melakukannya dua kali sebulan.

Tindakan responden menjemur kasur, bantal dan guling, sebanyak 35 responden (36,8\%) menjemur seminggu sekali. Sebanyak 26 responden $(27,4 \%)$ jarang atau tidak teratur menjemur kasur. Sebanyak 20 responden $(21,1 \%)$ menjemur sekali sebulan dan 14 responden (14,7\%) menjemur dua kali sebulan.

Dari hasil penelitian menunjukkan 94 responden $(98,9 \%)$ membuka jendela rumah setiap hari dan 1 responden (1,1\%) jarang membuka jendela rumah. Membuka jendela rumah setiap hari agar sinar matahari dapat masuk ke dalam rumah.

Tindakan responden bila ada anggota keluarga yang mengalami Alergi, sebanyak 56 responden $(58,9 \%)$ segera membawa penderita Alergi ke rumah sakit atau Puskesmas terdekat. Sebanyak 37 responden (38,9\%) mencoba mengobati sendiri karena sudah ada obatnya. Sedangkan yang tidak berobat ada 1 responden $(1,1 \%)$ dan tidak tahu harus melakukan apa ada 1 responden (1,1\%).

Berdasarkan perhitungan menurut kriteria penilaian didapatkan hasil 75,96\%. Hal ini menunjukkan bahwa tindakan sebagian besar responden dalam mencegah dan memberantas Tungau Debu Rumah sudah cukup. Dengan menyapu dan mengepel lantai setiap hari, serta membersihkan perabot rumah dengan menggunakan lap basah membantu keluarga terhindar dari debu dan Tungau Debu Rumah. Meletakkan pakaian dan buku-buku dalam lemari tertutup menghindari debu yang mudah menempel pada pakaian dan buku-buku. Dengan membuka jendela rumah setiap hari, membantu mengurangi kelembaban rumah karena sinar matahari yang masuk ke dalam rumah. ${ }^{1,4}$ Dan segera membawa penderita Alergi ke rumah sakit atau puskesmas membantu untuk meringankan kondisi penderita Alergi. 


\section{SIMPULAN}

Pengetahuan masyarakat kelurahan Perkamil mengenai tungau debu rumah masih kurang, tapi sikap terhadap upaya pencegahan dan pemberantasan tungau debu rumah sudah baik dan tindakan pencegahan serta pemberantasannya sudah cukup.

\section{UCAPAN TERIMA KASIH}

Terima kasih kepada dr. Runtuwene sebagai penguji 1 sekaligus pembimbing 1 , Dr. dr. J. S. B. Tuda, MKes, SpPar(K) sebagai penguji 2 sekaligus pembimbing 2, dr. V. D. Pijoh, MKes sebagai penguji 3 dan kepada semua pihak baik secara langsung atau tidak langsung telah menimbulkan ide untuk penulis sehingga artikel ini terselesaikan.

\section{DAFTAR PUSTAKA}

1. Susanto I, Ismid IS, Sjarifuddin PK, Sungkar S. Parasitologi Kedokteran. Edisi IV. Jakarta: Fakultas Kedokteran Universitas Indonesia, 2008.

2. Kuo LC, Yi FC, Cheong N, Shek LPC, Chew FT, Lee BW, et al. Sensitization to Blomia tropicalis and Dermatophagoides pteronyssinus - A Comparative Study between Singapore and Taiwan. Asian Pacific Journal Of Allergy And Immunology. 1999. 17 : 179-88.

3. Yudopranoto K. Perbandingan Populasi Tungau Debu Rumah Pada Kasur Kapuk dan Non Kapuk di Perumahan PJK Kelurahan Randusari Semarang Selatan Jawa Tengah. Semarang: Universitas Diponegoro, 2006.

4. Sungkar S. Aspek Biomedis Tungau Debu Rumah. Majalah Kedokteran Indonesia. 2004. 54(6) : 224 - 32.

5. Safar R. Parasitologi Kedokteran : Protozoologi, Helmintologi, Entomologi. Yrama Widya. Bandung: Yrama Widya, 2009.

6. Keadaan Iklim Kota Manado dan Letak Geografis. Posting : 28 Januari 2012. Diunduh : 16 Oktober 2012. Availabel from : http://manadokota.go.id/page-102iklim.html.

7. BPS Kota Manado. Geografis Kota Manado. Diunduh: 16 Oktober 2012. Availabel from: http://manadokota.bps.go.id/narasi.php?dat $\mathrm{a}=$ geografis. 